\title{
Microbial Biofilms Formed in a Laboratory-Scale Anammox Bioreactor with Flexible Brush Carrier
}

\author{
E. A. Botchkova ${ }^{*}$, Yu. V. Litti' ${ }^{1}$ B. B. Kuznetsov ${ }^{2}$, A. N. Nozhevnikova1 \\ ${ }^{1}$ Winogradsky Institute of Microbiology, Russian Academy of Science, Prospect 60-letiya Octyabrya 7, Moscow, \\ Russia \\ ${ }^{2}$ Center for Bioengineering, Russian Academy of Science, Prospect 60-letiya Octyabrya 7, Moscow, Russia \\ Email: ${ }^{*}$ botchkovaekat@gmail.com
}

Received 25 January 2014; revised 3 March 2014; accepted 16 March 2014

Copyright (C) 2014 by authors and Scientific Research Publishing Inc.

This work is licensed under the Creative Commons Attribution International License (CC BY).

http://creativecommons.org/licenses/by/4.0/

(c) (i) Open Access

\begin{abstract}
This study is focused on investigation of biofilms formed in an anaerobic laboratory-scale bioreactor fed with medium for anammox bacteria oxidizing ammonia with nitrite. The mixed culture of anammox bacteria was enriched from the microbial community that sampled from the activated sludge of a denitrifying reactor at a wastewater treatment station located in the Sochi region, Russia. This community forms biofilms on the surface of the flexible polymer brush carriers, which are used for biomass immobilization in both laboratory and full-scale bioreactors. Anammox bacteria were discovered in the activated sludge community. The anammox community was enriched by incubation in an up-flow laboratory-scale anaerobic bioreactor with a flexible brush carrier. In the course of $\sim 3$ years, the loading rate of nitrogen substrates (ammonium and nitrite) increased from 100 to $5000 \mathrm{mg} \mathrm{N} \mathrm{L}^{-1}$ day $^{-1}$. The concentration of the substrates in the upper part of the reactor was 40 times less than in the influent. The pH values were 7.5 at the bottom and up to 9 in the upper part up of the reactor. Biofilms of two types developed in the reactor. Bunches of irregular spherical granules formed on the carrier filaments, while films of irregular thickness containing submerged spherical granules were formed on the walls of reactor. The anammox population was found to consist of at least three active species: a new strain of Candidatus "Jettenia asiatica" named "strain ecos" and two species of the genus Candidatus "Brocadia". Other types of bacteria found in the community, including members of phylum Chloroflexi, were presumably involved in biofilm spatial organization.
\end{abstract}

\section{Keywords}

Anammox; Anammox-Bacteria; Biofilm; Microbial Community; Chloroflexi

\footnotetext{
"Corresponding author.

How to cite this paper: Botchkova, E.A., Litti, Y.V., Kuznetsov, B.B. and Nozhevnikova, A.N. (2014) Microbial Biofilms Formed in a Laboratory-Scale Anammox Bioreactor with Flexible Brush Carrier. Journal of Biomaterials and Nanobiotechnology, 5, 76-82. http://dx.doi.org/10.4236/ibnb.2014.52010
} 


\section{Introduction}

Wastewater treatment is presently one of the key environmental problems. The activated sludge process, which is the procedure most commonly used in both small settlements and big cities, relies on dispersed growth. Among its most serious disadvantages are aerosol formation, high energy requirements, considerable land alienation and formation of significant amounts of waste activated sludge which requires disposal. The lack of suitable wastewater treatment technology to remove nitrogen and phosphorous compounds, which cause water eutrophication and may be carcinogenic, is among the most serious disadvantages of the process. Nitrogen removal may be achieved by carrying out nitrification and denitrification processes in a single reactor with alterating oxic/anoxic conditions, recycling of treated water from an aerotank to a denitrification reactor, or by using a separate denitrification stage. Anammox bacteria, a chemolithoautotrophic group of microorganisms discovered about 15 years ago [1], are responsible for anaerobic ammonium oxidation with nitrite ions and result in formation of molecular nitrogen according to the following equation:

$$
\mathrm{NH}_{4}^{+}+\mathrm{NO}_{2}^{-}=\mathrm{N}_{2}+2 \mathrm{H}_{2} \mathrm{O}
$$

This group of microorganisms belong to the phylum Planctomycetes and include 13 candidate species. They are characterized by extremely low growth rates and unusual cell structure. Discovery of new species of anammox bacteria remains an important task both for fundamental science and biotechnology.

Anammox bacteria in both natural and anthropogenic ecosystems have a strong tendency to attach to surfaces and form biofilms. They therefore demonstrate extremely high robustness under changing environmental conditions and firm adhesion to solid surfaces. Cell division results in formation of microcolonies surrounded by a dense membrane. Previously reported studies on anammox biofilms mention that such biofilms appear to be highly heterogeneous formations, consisting of densely packed biomass and interstitial voids.

None of the anammox bacterial species have been isolated in pure culture since their discovery in 1999. They are found as members of mixed microbial communities, co-existing with other species of bacteria and archaea. Complicated relationships between anammox bacteria and other members of these communities may be responsible for the high level of population stability and robustness to environmental changes.

Our research of anammox bacteria was aimed at development of an efficient method for microbial nitrogen removal from wastewater. Based on our studies, a novel advanced wastewater treatment technology with high level of nitrogen removal was developed and new wastewater treatment plants (WWTPs) were constructed. This technology provides favorable conditions for growth of anammox bacteria by using brush carriers for immobilization of activated sludge at all stages of treatment, recycling of treated water from the aerobic bioreactor to the anaerobic denitrifying reactor, etc. [2] [3]. Investigation of nitrogen and carbon consumption by the microbial population developed at the new wastewater treatment plant showed that the biomass was immobilized both at the surface of polymer carriers and as biofilms. Anaerobic microniches formed even under vigorous aeration, and anaerobic bacteria, including such obligate anaerobes as methanogenic archaea and anammox bacteria, constituted at least $10 \%$ of the total microbial population. Under these conditions they remained active and performed methanogenesis and anaerobic ammonium oxidation [4]. Due to activity of anaerobic microorganisms in the biofilms, production of excess sludge was significantly lower, and nitrogen compounds were removed very efficiently, since anammox bacteria have a high affinity to nitrogenous substrates [1].

The main goals of this work were to study the community of anammox bacteria, its ability to form biofilms in a laboratory-scale bioreactor, the groups of microorganisms involved in biofilm formation, and the adaptation of these biofilms to gradually increasing nitrogen concentrations.

The subjects of this study were samples of microbial biofilms developed in a laboratory-scale reactor inoculated with attached activated sludge from a full-scale WWTP located at the construction site of 2014 Winter Olympics in Sochi.

\section{Materials and Methods}

Cultivation of Anammox Bacteria. The medium described in [3] was used with slight modifications for batch and continuous cultivation of anammox bacteria. In order to remove dissolved oxygen, freshly prepared medium was purged with argon. The biomass of anammox bacteria was enriched by feed-batch cultivation in a 3 - 1 reactor for 4 months. Once a week, $2 \mathrm{l}$ of the liquid was replaced with fresh medium and the substrates (nitrite and ammonium) were added if required as stock solutions. The following parameters were determined at least 
weekly: $\mathrm{pH}$, composition of the gaseous phase and concentrations of nitrite, nitrate, and ammonium ions. The concentrations of dissolved organic substances (in terms of chemical oxygen demand) and volatile fatty acids were measured once every 3 - 4 weeks.

Cultivation of anammox bacteria and investigation on the growth parameters were performed in a hybrid upflow anaerobic laboratory bioreactor with flexible polymer carriers (brushes) for cell immobilization. The reactor was operated at $30^{\circ} \mathrm{C} ; \mathrm{pH}$ and the concentrations of nitrite, nitrate, and ammonium concentration were monitored in the influent and effluent. Nitrogen load was gradually increased by increasing the substrate concentration and flow rate [3]. After 3 years of cultivation, nitrogen load reached $5 \mathrm{~g} \mathrm{~N} /(\mathrm{l}$ day).

Chemical analyses were performed as described previously [3]. Oxygen, nitrogen, hydrogen, and methane were monitored on a Crystal 50001 gas-liquid chromatograph (CHROMATECH, Yoshkar-Ola, Russia) and a CHROM-5 gas chromatograph (Czechoslovakia). Volatile fatty acids (VFA) were analyzed on a Stayer highperformance liquid chromatograph (HPLC) (Russia). Chemical oxygen demand was measured by the dichromate method. Nitrate was measured colorimetrically, nitrite and ammonium were measured according to the standard Lurie method, and pH was measured on a HANNA pH-211 pH-meter (Germany). Dry mass was measured gravimetrically after heating to constant weight $\left(24 \mathrm{~h}\right.$ at $\left.105^{\circ} \mathrm{C}\right)$.

Morphology and ultrastructure of the microorganisms was studied under an Olympus phase contrast microscope and a JSM-T300 scanning electron microscope (Japan). Ultrathin sections of anammox microcolonies were exmined under a JEM 100C transmission electron microscope (Jeol, Japan) at $80 \mathrm{kV}$.

In situ detection of anammox bacteria in biofilms was performed by FISH with the PLA46 and Amx368 probes for detection of anammox Planctomycetes as described previously [3].

Phylogenetic Studies. Samples for phylogenetic studies were taken from the upper and lower parts of the reactor. DNA was extracted according to the modified method described previously [5]-[7] using the Wizard-technology reagent kit (Promega, USA). The 16S rRNA genes were amplified by PCR with the 11F and 1492R primers [8]. Amplification primers Pla 46F and 1385R were used for Planctomycete-specific gene fragments [9]. E. coli clones were transformed by the recombinant plasmid with integrated oligonucleotide sequences from anammox bacteria, amplified in PCR. DNA was extracted from the clones according to the same method [5]. The sequencing was carried out as described previously [10] with an ABI PRIZM 3730 automatic sequencer according to the manufacturer's recommendations.

The sequences were edited, analyzed and compared to the sequences from the GenBank by means of NCBI Blast (http://www.ncbi.nlm.nih.gov/blast) and BioEdit programs (http://jwbrown.mbio.ncsu.edu/BioEdit/bioedit.html). The sequences chosen for subsequent manipulations were aligned by means of CLUSTAL W v 1.75 algorithm [11] and checked to exclude chimeras at Find Chimeras (http://decipher.cee.wisc.edu/FindChimeras.html). The phylogenetic tree was constructed by means of MEGA 5.0 program.

Results and Discussion. Large amounts of the activated sludge biomass enriched with anammox bacteria was obtained in the laboratory-scale continuous-flow bioreactor. According to chemical analyses, the anammox process, i.e. dinitrogen production coupled to ammonium oxidation with nitrite, occurred in the bioreactor. The microbial population responsible for the anammox population was active, not only surviving high concentrations of nitrogen compounds, but successfully converting them into molecular nitrogen. In the course of cultivation, anammox activity increased gradually (Figure 1). The ratio of consumed nitrite and ammonia (1.32) was close to the theoretical value.

Parameters of the medium ( $\mathrm{pH}$ and nitrogen concentrations) were not the same in various parts of the reactor, with a pronounced vertical concentration gradient of nitrogen substrates and $\mathrm{pH}$ (Table 1). Thus, co-existence of different strains or species of anammox bacteria was possible in different parts of the bioreactor.

Microbial biomass in the reactor was mostly under attached, forming biofilms. The biomass was of intensive red-brown color, indicating predomination of anammox bacteria. Biofilms developed in all parts of the bioreactor on the surface of the brush fibers and on the walls of the reactor. All of them belonged to two groups, differing in shape, spatial organization and, presumably, composition (Figures 2(a) and (b)).

The biofilms developing on the filaments of polymer carriers were of intensive red color, spherical shape, and relatively dense structure. Such biofilms (type 1) formed bunches on the surface of the flexible carriers. The biofilms of this kind occurred at all levels of the bioreactor, from the bottom to the top (Figure 3(a)). The biofilms of another kind (type 2 biofilms) developed on the surface of the bioreactor walls (Figure 3(b)). The color of type 2 biofilms was also red-brown indicating that the anammox cells in this biofilms were active and numerous. Unlike type 1 biofilms, biofilms of this type were relatively thin, less dense, and easily broken. The biofilms of 


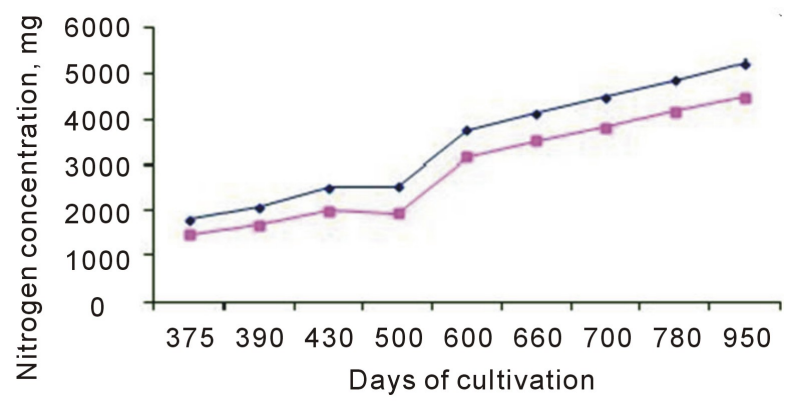

Figure 1. Performance of the anammox reactor as a function of operating time. Profiles for total nitrogen load (mg N/l per day; diamonds) and total nitrogen removal (mg N/l per day; squares) at 375 - 950 days of cultivation are shown..

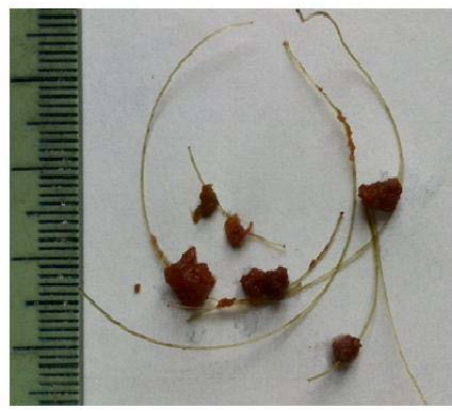

(a)

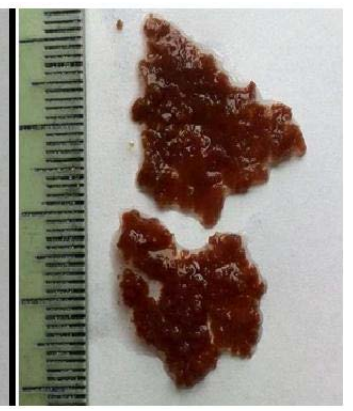

(b)

Figure 2. Anammox biofilms. A-type 1 biofilm, B-type 2 biofilm. Small bar, $1 \mathrm{~mm}$.
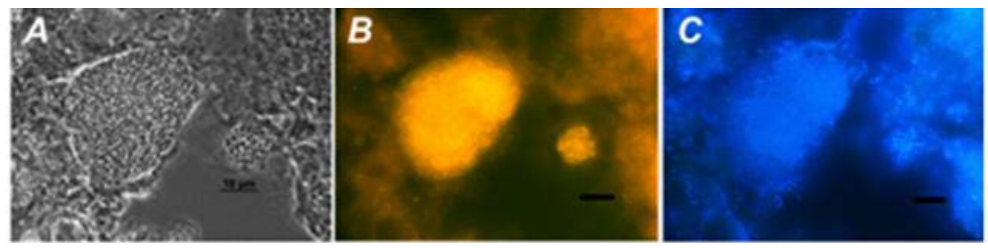

(a)
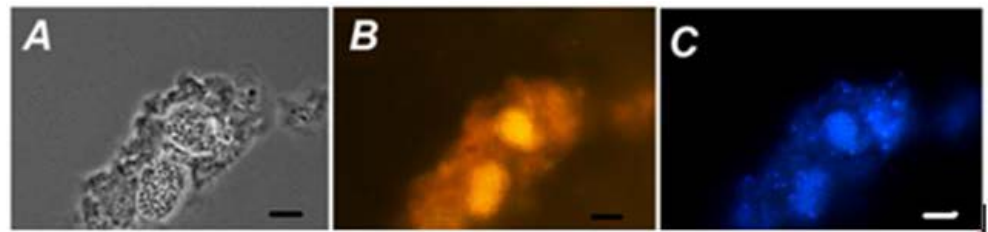

(a)

Figure 3. Samples of biofilms from the bottom (a) and the top (b) part of the reactor, stained with the anammox-specific probe Amx368: A-phase contrast image; B-microphotographs of hybridization with the probe, C-DAPI staining. Bar, $10 \mu \mathrm{m}$.

Table 1. Comparison of environmental conditions at the bottom and top parts of the reactor.

\begin{tabular}{ccc}
\hline Parameters & Bottom part & Top part \\
\hline $\mathrm{NH}_{4}$ concentration, $\mathrm{mg} / \mathrm{l}$ & $340-350$ & $8-10$ \\
$\mathrm{NO}_{2}$ concentration, $\mathrm{mg} / \mathrm{l}$ & $350-365$ & $7.5-9.5$ \\
$\mathrm{pH}$ & $7.5-7.6$ & $8.8-9.0$ \\
\hline
\end{tabular}


this type develop also on the surface of the effluent collector and inside the tubes for effluent removal. Anammox community in type 2 biofilms was adapted to starvation, since only trace amounts of ammonium and small amounts of nitrite were available in the effluent (Table 1).

The results of FISH analysis with anammox-specific probes confirmed the abundance of active anammox bacteria in both types of biofilms (Figure 3).

According to electron microscopy (Figure 4), anammox microcolonies at the bottom part of the reactor varied in size and had regular shape with oval cells inside, embedded into a dense layer of glycocalyx. The cells had typical anammox ultrastructure and compartmentalization (Figure 4(a)). Other cells with morphology atypical for anammox bacteria were observed. These cells could be seen outside the glycocalyx-covered conglomerates of anammox cells. Aggregates of smaller cells with the ultrastructure not typical of anammox bacteria (presumably, Chloroflexi-like bacteria) could be observed outside the membrane and the glycocalyx layer (Figure 4(b)).

Phylogenetic study confirmed that the activated sludge wasa complex community containing microorganisms of different phylogenetic groups (Figure 5). The bottom and the upper part of the reactor differed in the composition of the anammox population. According to the phylogenetic studies, anammox population in the bottom part of the reactor consisted of at least three different anammox species. On Figure 5 these operational taxonomic units (OTUs) are named "Anammox-1, 2 and 3". The clone library of the sequences obtained by PCR with Planctomycetes-specific primers included 88 clones, $~ 55 \%$ of them forming one compact monophyletic group inside the phylum Planctomycetes, which was $98 \%$ identical to the sequence belonging to the anammox bacteria Candidatus 'Jettenia asiatica' (GenBank accession no. DQ301513.1). This group of anammox bacteria was discovered in both higher and lower parts of the reactor (OTU "Anammox-1" on Figure 5). Two minor components of the anammox community, both retrieved from the lower part of the reactor, belonged to different species of the genus Candidatus "Brocadia” "Anammox-2" and "Anammox-3" respectively). The relationships among these co-existing anammox species might be complex, mutually beneficial as well as competitive.

Only one species of anammox bacteria, OTU "Anammox-1" from the bottom part was detected in the microbial population of the upper part of the reactor. Thus, Candidatus "Jettenia asiatica" strain "ecos" was probably the most robust member of the anammox community, able to grow under different physiological conditions. It is also possible that another strain of Candidatus "Jettenia asiatica" developed in upper part of reactor. In any case, members of the species Candidatus "Jettenia asiatica" were able to survive both starvation and high amounts of nitrogen substrates, although high concentrations of nitrite were reported to be toxic for anammox bacteria [12]. It is therefore possible to use the strains of Candidatus "Jettenia asiatica" for treatment of wastewaters with both low and high concentrations of nitrogen-an important feature for biotechnological application of anammox bacteria.

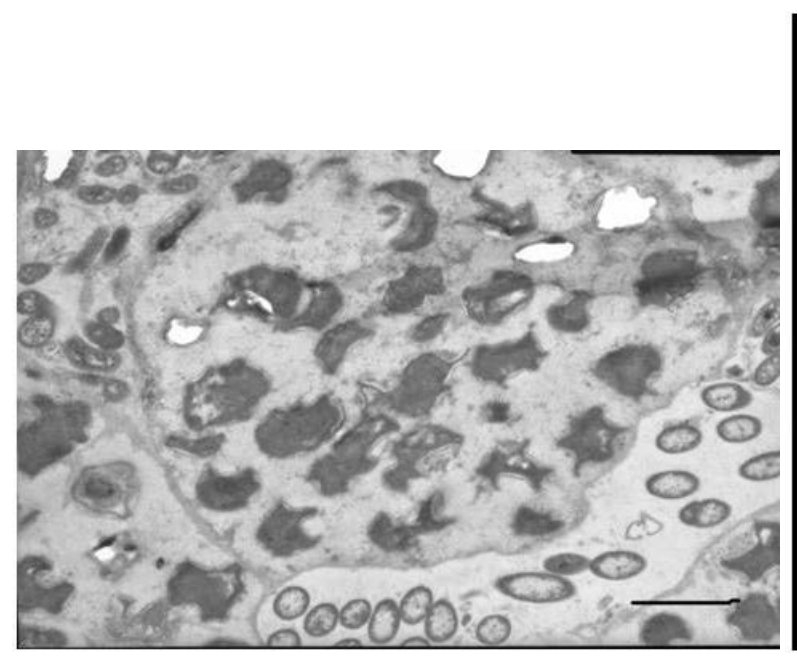

(a)

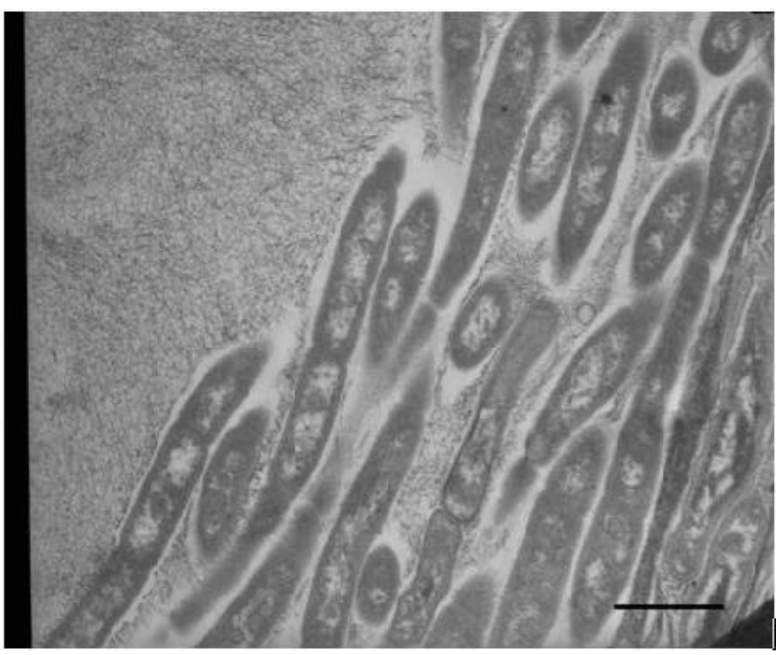

(b)

Figure 4. (a). Transmission electron micrograph of thin-sectioned chemically fixed type 1 biofilm taken from flexible carrier. Bar: $1 \mu \mathrm{m}$. (b). Transmission electron micrograph of thin-sectioned chemically fixed filamentous cells (presumably, Chloroflexi-like bacteria) from type 1 biofilm. Bar, $0.5 \mu \mathrm{m}$. 


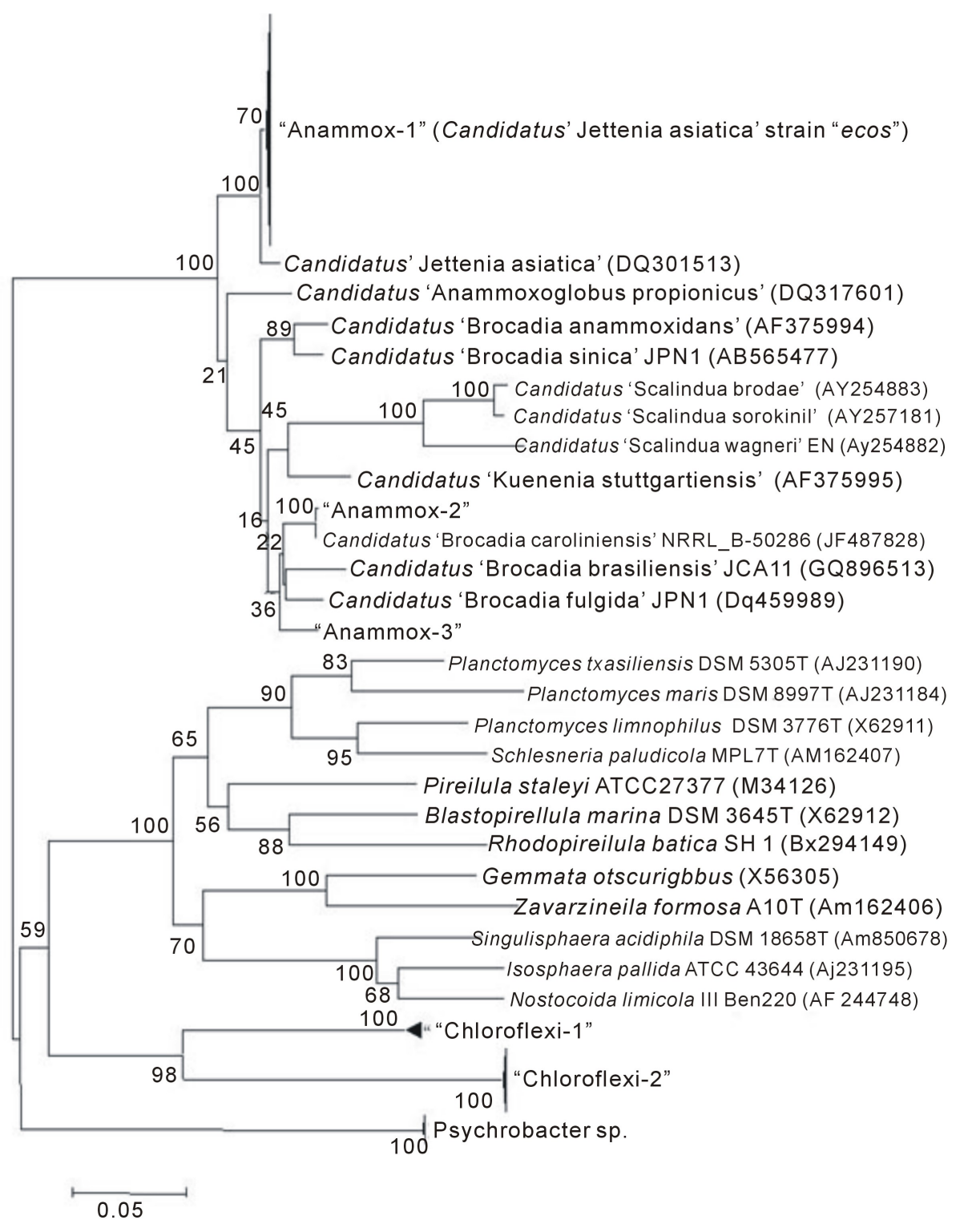

Figure 5. Phylogenetic tree of $16 \mathrm{~S}$ rRNA gene sequences obtained using the Planctomycetesspecific primer. The tree reflects the position of anammox bacteria and other members of community of the bottom part of the bioreactor among other members of Planctomycetes. The OTUs obtained in this study are shown in boldface. The tree was calculated with maximum likelihood method based on the analysis of 1000 alternative trees. The values at the nodes reflect bootstrap-analysis reliability. The bar reflects the scale of evolutionary distance. Neighbor-joining algorithm was used.

Phylogenetic studies also confirmed the presence of various bacteria from different phylogenetic groups within the activated sludge microbial community. For instance, uncultured members of the phylum Chlorofexi belonging to two different phylotypes were revealed in the community. One of them, "Chloroflexi-1", was represented by 8 clones, another-by 25 clones. Co-existence of anammox bacteria with these obviously heterotrophic bacteria has already been reported [13] [14]. Filamentous cell structure is typical of this group of bacteria. It means that in such anthropogenic microbial community as activated sludge from wastewater treatment plants, Choroflexi-like bacteria can play an important role in formation of anammox aggregates. Their occurrence in such communities might be very important for successful formation of biofilms and their spatial organization. Cross-sections of the cells probably belonging to the filamentous morphotype are presented on Figure 4(b). 
Occurrence of the Betaproteobacteria was also shown by using $11 \mathrm{~F}$ and $1492 \mathrm{R}$ bacterial primer set. This group might be responsible for consumption of trace amounts of $\mathrm{O}_{2}$ or organic compounds, providing suitable conditions for growth and development of anammox bacteria.

\section{Conclusion}

The studied microbial community had a complicated multicomponent structure. The presence of different species of anammox bacteria and other accompanying microorganisms, together with the remarkable ability of anammox bacteria to form biofilms, consisting of microcolonies surrounded by a dense membrane, provided for stability of this type of community and its ability to survive and function under varying environmental conditions.

\section{References}

[1] Strous, M., Fuerst, J.A., Kramer, E.H., Logemann, S., Muyzer, G., van de Pas-Schoonen, K.T., Webb, R., Kuenen, J.R. and Jetten, M.S. (1999) Missing Lithotroph Identified as New Planctomycete. Nature, 400, 446-449. http://dx.doi.org/10.1038/22749

[2] Nozhevnikova, A.N., Simankova, M.V. and Litti, Yu.V. (2012) Application of the Microbial Process of Anaerobic Ammonium Oxidation (ANAMMOX) in Biotechnological Wastewater Treatment. Applied Biochemistry and Microbiology, 48, 667-684. http://dx.doi.org/10.1134/S0003683812080042

[3] Nozhevnikova, A.N., Litti, Yu.V., Nekrasova, V.K., Kulichevskaya, I.S., Grigoryeva, N.V., Kulikov, N.I. and Zubov, M.G. (2012) Anaerobic Ammonium Oxidation (Anammox) in Immobilized Activated Sludge Biofilms during the Treatment of Weak Wastewater. Microbiology, 81, 25-34.

[4] Litti, Yu.V., Nekrasova, V.K., Kulikov, N.I. and Nozhevnikova, A.N. (2013) Detection of Anaerobic Processes and Microorganisms in Immobilized Activated Sludge of a Wastewater Treatment Plant with Intense Aeration. Microbiology, 82, 690-697. http://dx.doi.org/10.1134/S0026261713060076

[5] Birnboim, H.C. and Doly, J. (1979) A Rapid Alkaline Extraction Procedure for Screening Recombinant Plasmid DNA. Nucleic Acids Research, 7, 1513-1523. http://dx.doi.org/10.1093/nar/7.6.1513

[6] Zhou, J., Bruns, M.A. and Tiede, J.M. (1996) DNA Recovery from Soils of Diverse Composition. Applied Environmental Microbiology, 62, 316-322.

[7] Krsek, M. and Wellington, E.M.H. (1999) Comparison of Different Methods for the Isolation and Purification of Total Community DNA from Soil. Journal of Microbiological Methods, 39, 1-16.

[8] Lane, D.J. (1991) 16S/23S Sequencing. In: Stackebrandt, E. and Goodfellow, M., Eds., Nucleic Acid Techniques in Bacterial Systematic, John Wiley \& Sons, Ltd., Chichester, 115-175.

[9] Li, M., Hong, Y., Klotz, M.G. and Gu, J.-D. (2010) A Comparison of Primer Sets for Detecting 16S rRNA and Hydrazine Oxidoreductase Genes of Anaerobic Ammonium-Oxidizing Bacteria in Marine Sediments. Applied Microbiology and Biotechnology, 86, 781-790. http://dx.doi.org/10.1007/s00253-009-2361-5

[10] Sanger, F., Nicklen, S. and Coulson, A.R. (1977) DNA Sequencing with Chain-Terminating Inhibitors. Proceedings of the National Academy of Sciences, 84, 5463-5467. http://dx.doi.org/10.1073/pnas.74.12.5463

[11] Thompson, J.D., Higgins, D.G. and Gibson, T.J. (1994) CLUSTAL W: Improving the Sensitivity of Progressive Multiple Sequence Alignment through Sequence Weighting, Positions-Specific Gap Penalties and Weight Matrix Choice. Nucleic Acids Research, 22, 4673-4680. http://dx.doi.org/10.1093/nar/22.22.4673

[12] Strous, M., Kuenen, J.G. and Jetten, M.S.M. (1999) Key Physiology of Anaerobic Ammonium Oxidation. Applied and Environmental Microbiology, 65, 3248-3250.

[13] Cho, S., Takahashi, Y., Fujii, N., Yamada, Y., Saton, H. and Okabe, S. (2010) Nitrogen Removal Performance and Microbial Community Analysis of an Anaerobic Up-Flow Granular Bed Anammox Reactor. Chemosphere, 78, 11291135. http://dx.doi.org/10.1016/j.chemosphere.2009.12.034

[14] Kindaichi, T., Yuri, S., Ozaki, N. and Ohashi, A. (2012) Ecophysiological Role and Function of Uncultured Chlorofle$x i$ in an Anammox Reactor. Water Science Technology, 66, 2556-2561.

http://dx.doi.org/10.2166/wst.2012.479 